\title{
O uso do TikTok no contexto educacional
}

\author{
Claudia Smaniotto Barin - PPGEPT/UFSM - claudiabarin@ufsm.br \\ Ricardo Machado Ellensohn - PPGEPT/UFSM - UNIPAMPA/Caçapava do Sul - \\ ricardoellensohn@gmail.com \\ Marcelo Freitas da Silva - PPGEPT/UFSM - marcelo@ctism.ufsm.br
}

\begin{abstract}
Resumo: O uso de recursos da tecnologia no contexto educacional vem sendo discutido nas últimas décadas, no entanto com a necessidade do distanciamento social decorrente do Covid-19, a disruptura tornou-se mais evidente. Nesse sentido, o trabalho consiste de um relato de experiência sobre o uso da rede social TikTok no contexto educacional. Metodologicamente apoiados no Design Based Research, produziu-se uma proposta de design, visando engajar os estudantes, matriculados na disciplina de Química, no processo de aprendizagem. Com base nos resultados afirmamos que vídeos curtos têm potencial para despertar o interesse dos estudantes pelo conteúdo e, que a abordagem humorística contida nos vídeos TikTok, contribui para um aprendizado mais agradável. Assim, o TikTok pode ser útil tanto para distribuição de conteúdo quanto para avaliação.
\end{abstract}

Palavras-chave: Redes Sociais. Distribuição de conteúdo na Web. Mediação tecnológica.

\section{The use of TikTok in the educational context}

Abstract: The use of technology resources in the educational context has been discussed in recent decades, however, with the need for social distance resulting from Covid-19, the disruption has become more evident. In this sense, the work consists of an experience report on the use of the social network TikTok in the educational context. Methodologically supported by DBR, a design proposal was produced, aiming to engage students, enrolled in the discipline of Chemistry, in the learning process. Based on the results we affirm that short videos have the potential to arouse students' interest in the content and that the humorous approach contained in the TikTok videos contributes to making learning more enjoyable. Thus, TikTok can be useful for both content distribution and evaluation.

Keywords: Social Media. Web Content distribution. Technological Mediation.

\section{Introdução}

Em 2020 a pandemia do Corona vírus - Covid19 - em um curto espaço de tempo, trouxe uma série de mudanças tanto nas relações sociais, como no mundo do trabalho e na educação (Valente, 2020). Depois de décadas de discussão sobre as potencialidades e os desafios da incorporação das tecnologias como elemento de mediação pedagógica, seu uso ampliou-se mundialmente, devido à obrigatoriedade do distanciamento social.

Assim, o uso dos ambientes virtuais de ensino e aprendizagem (AVEA) tiveram um crescimento considerável, sendo uma das formas de promover a continuidade das atividades de ensino, tanto em nível regional, como nacional e internacional. No entanto, o uso dos AVEA por si só, não são garantia de aprendizado, visto que se faz 
necessário transpor saberes de forma a tornar a mediação tecnológica viável e flexível, atendendo as necessidades dos estudantes. Ademais, soma-se a isso as questões relacionadas à inclusão digital e a acessibilidade dos estudantes.

Considerando as adaptações necessárias decorrentes do distanciamento social, as redes sociais despontaram como uma possibilidade de integração das tecnologias para fins educacionais. Dentre as redes sociais o Facebook, se destaca, sendo a rede mais citada estudos e publicações científicas. Rosado e Alves (2018) afirmam que o uso do Facebook por docentes tem propiciado espaços de discussão e compartilhamento de saberes e, que essa estratégia apesar de ter possibilidade de gerar tensões, pode contribuir para a valorização da profissão docente. De Oliveira e Nichele (2019) apontam para a viabilidade da utilização do Facebook como AVEA e a potencialidade da rede social para mediar os processos de ensino e aprendizagem. Esse potencial é também apontado por Soares et al (2018).

No entanto, apesar das redes sociais serem estudadas como alternativa viável para o processo de ensino e aprendizagem, poucos trabalhos exploram o uso do TikTok para esse fim. O TikTok é uma rede social de vídeos disponível tanto para sistemas operacionais Android como para iOS e permite ao usuário - tiktoker - a produção de vídeos curtos de 15 a 60 segundos e sua publicação em um Feed. No último ano, essa plataforma foi apontada como o app mais baixado na App Store, superando o Facebook e o Instagram e encontra-se entre as mídias sociais mais acessadas no mundo. Segundo o TikTok, o principal objetivo do mesmo é trazer alegria e incentivar a criatividade para seus usuários.

De acordo com Wang (2020), os vídeos curtos para celular como os do TikTok estão cada vez mais populares, o que segundo o autor pode estar associado ao comportamento humano-máquina, pois a visão da câmera em primeira pessoa, eleva a imersão e interação social. Esse fato pode ser explicado ainda, pelo que afirmam Da Rocha e Farias (2020) que "A riqueza de informação cria pobreza de atenção", ou seja os vídeos curtos mantém a atenção por maior tempo.

Monteiro (2020) afirma que o TikTok pode ser usado não apenas para diversão, mas também para a distribuição de conteúdos criativos, para integração dos estudantes e o desenvolvimento do potencial criativo dos mesmos, assim como instrumento de avaliação da aprendizagem.

A potencialidade do uso de vídeos no processo de ensino e aprendizagem já tem sido amplamente discutida na literatura como nas abordagens de Moran (1995) e Felcher, Bierhalz e Fommer (2019). Dentre as potencialidades os autores destacam a possibilidade de reuso, permitindo aos estudantes e interessados, assistir ao vídeo, tantas vezes forem necessárias para a compreensão do mesmo, o que não ocorre no ambiente de sala de aula, onde por limitações temporais, o professor precisa dar continuidade ao assunto, ou ainda, em função da timidez, o estudante opta por não informar que ainda possui dúvidas sobre o conteúdo ou que não o compreendeu.

Dentre os desafios do uso dos vídeos como proposta pedagógica, Moran (1995) destaca que o mesmo deve ter uma intencionalidade educativa, não sendo apenas mero instrumento de distração ou para cobrir planejamentos mal construídos. Assim, o professor ao escolher o vídeo leve levar em conta o público-alvo, a faixa etária do mesmo, os conteúdos a serem trabalhados e se a abordagem possui a profundidade adequada.

Felcher, Bierhalz e Fommer (2019) ressaltam ainda, que o interesse dos estudantes pela plataforma YouTube impõem aos professores o desafio de repensar sua 
práxis, não como solução aos problemas da educação, mas como um recurso alternativo que poderá contribuir no processo de formação dos seus alunos.

Nesse sentido, o presente trabalho visa apresentar e discutir as vantagens e os desafios da experiência do uso do TikTok como elemento de distribuição de conteúdos, mediação e avaliação.

\section{Metodologia}

Apoiados no Design Based Research (DBR), após observar a realidade e identificar um problema real (o desinteresse dos estudantes pelo aprendizado remoto), foram planejados, criados e disponibilizados vídeos conteudistas criados no TikTok, com o intuito de despertar o interesse pelo aprendizado e engajá-los no processo de construção do conhecimento. A Figura 1 apresenta um esquema da DBR.

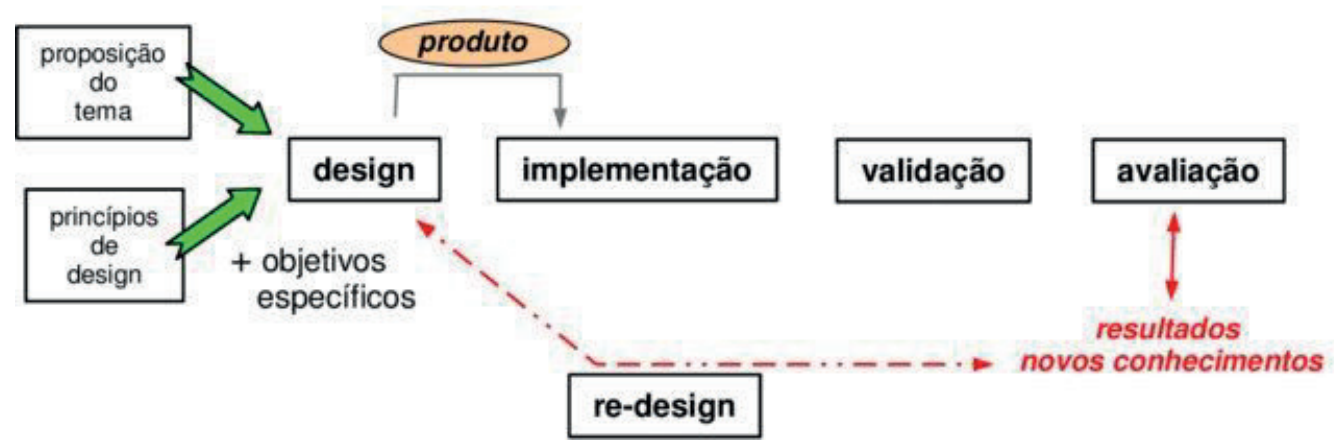

Figura 1 - Esquema da estrutura do Design Based Research

Fonte: Botelho Kneubil e Pietrocola (2019)

A DBR consiste em uma metodologia intervencionista que busca aliar aspectos teóricos da pesquisa em educação com a prática educacional em contextos reais, por meio dos ciclos iterativos de design, desenvolvimento, implementação, análise e redesign, em busca de soluções para os problemas/desafios da educação, criando artefatos pedagógicas e gerando os princípios de design (Wang; Hannafin, 2005; Herrington et al., 2007).

O público-alvo consistiu de 46 estudantes recém-ingressantes na Universidade, tendo de idade entre 17 e 24 anos. Os estudantes tiveram apenas 1 semana de aula presencial e logo necessitaram retornar para suas cidades devido a pandemia do Covid19. Assim, a disciplina que ocorria de forma presencial, passou a ser mediada no ambiente virtual Moodle, sendo as unidades de estudo disponibilizadas semanalmente.

Os materiais disponibilizados eram variados, contendo links a artigos, textos produzidos pelos docentes, vídeo-aulas, podcasts, mapas conceituais, bem como os vídeos do TikTok, sendo os resultados desse último descrito a seguir. Numa perspectiva de redesign, ao final da disciplina os estudantes foram instigados a se tornarem autores de conteúdo, produzindo seus próprios vídeos. 


\section{Desenvolvimento}

O primeiro passo para a produção dos vídeos, foi a aquisição da fluência tecnológica na plataforma TikTok, para isso foi necessário a gravação de uma série de vídeos, usando os efeitos disponibilizados pelo App (Figura 2).

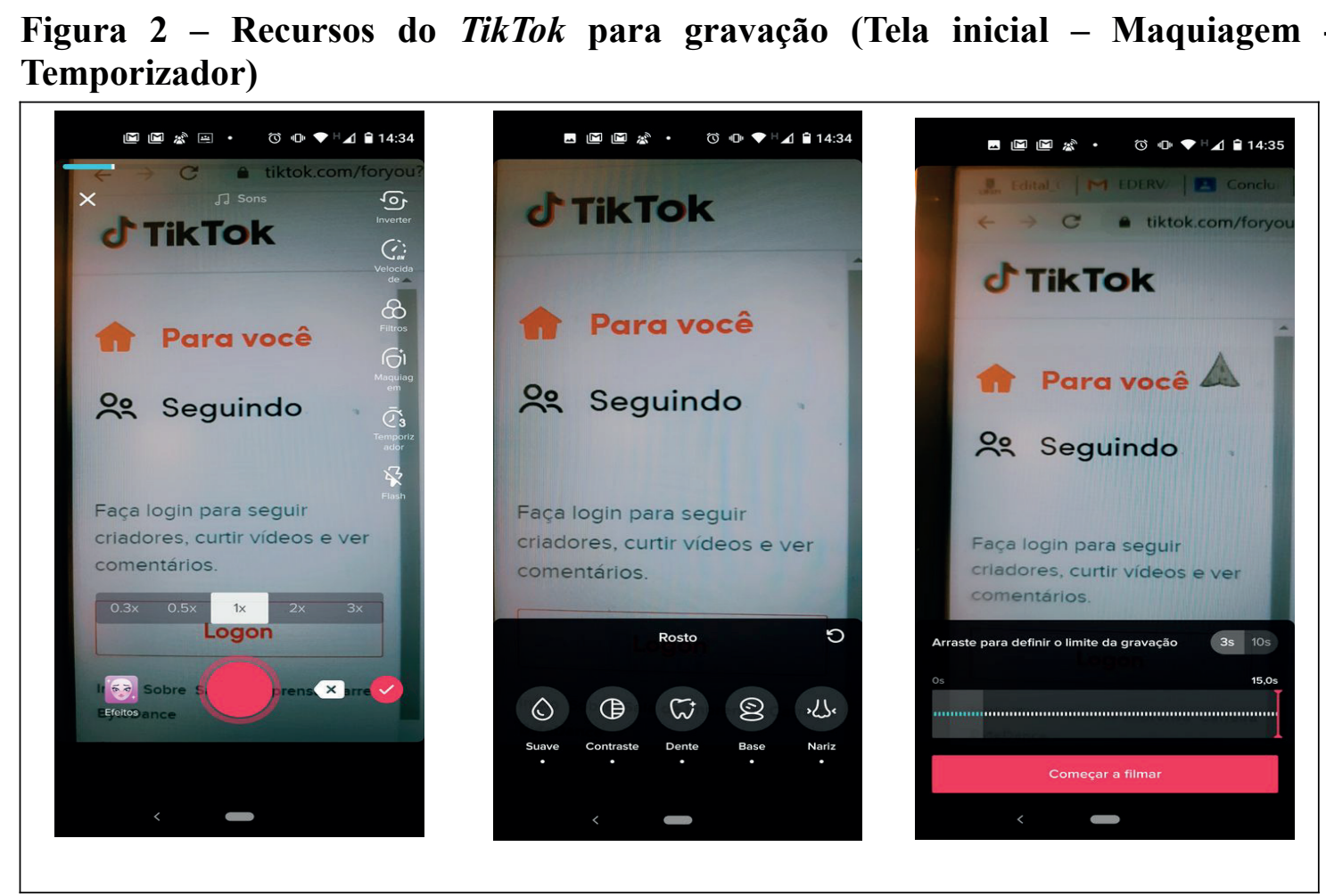

Fonte: os autores.

Como pode-se observar na Figura 2, o TikTok apresenta alguns recursos como (1) escolha da câmera de captura (frontal ou posterior); (2) velocidade de gravação; (3) filtros, que permitem controlar a tonalidade e a luminosidade do meio; (4) maquiagem, que possibilita modificar digitalmente a composição do personagem, como, por exemplo, branqueamento dos dentes, uso de base, rinoplastia, harmonização facial, etc.; (5) temporizador, o qual permite escolher que a gravação do vídeo inicie em 5 ou 15 segundos automaticamente e (6) flash.

Após a aquisição da fluência, deu-se início ao processo de roteirização, ou seja, do processo de design do produto. A criação de um roteiro requer inicialmente a definição de um conteúdo. Considerando que a produção do mesmo tem uma intencionalidade educacional, apoiados em Moran (1995), podemos afirmar que o processo de roteirização requer o movimento da transposição de saberes, de forma a adequar o conteúdo ao público ao qual se destina.

$\mathrm{O}$ esquema de roteirização criado pode ser visualizado na Figura 3. 
Figura 3 - Esquema de roteirização

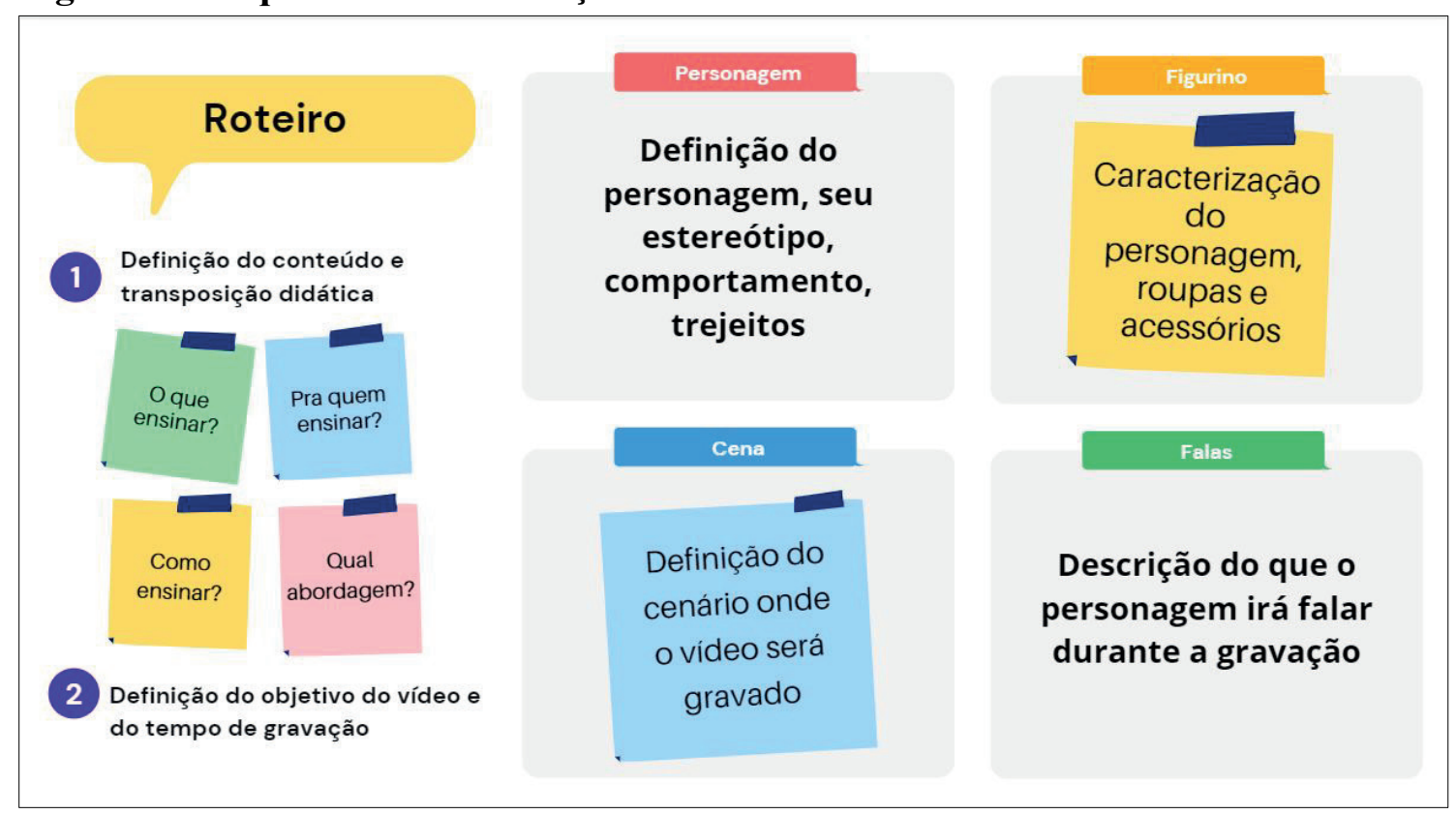

Fonte: os autores.

Respondidas as questões relativas ao processo de adaptação do conteúdo, o objetivo ou intencionalidade do vídeo e o tempo de duração, deu-se início ao processo de construção do personagem. A ideia de criação da "Cláudia Hermínia" surgiu após assistir uma série de dublagens da personagem do Filme "Minha mãe é uma peça". No entanto, como no TikTok só existiam áudios de trechos do filme para dublagem, foi necessário a criação de um personagem, que teve como fonte de inspiração a Dona Hermínia, do filme citado.

O processo de produção do vídeo foi feito no dispositivo móvel, por meio do app do TikTok. Inicialmente escolheu-se o tempo de vídeo (60 segundos) e logo a seguir acionou-se o temporizador, para dar início a gravação. $\mathrm{O}$ temporizador é um recurso interessante pois possibilita ao criador, preparar-se para o início do vídeo, não sendo necessário fazer edições para cortar movimentos decorrentes da ação de iniciar ou parar a gravação.

Durante a produção midiática não utilizou-se nenhum efeito de som, apenas filtros de maquiagem para a composição do personagem "Claudia Hermínia". A composição da cena era dependente não apenas do contexto da personagem, como das condições climáticas do período de gravação. As gravações ocorreram tanto em ambiente interno como externo, com ou sem o auxílio de outra pessoa para efetivação da filmagem.

A distribuição do conteúdo (fase de implementação) se deu não apenas no ambiente virtual Moodle, como também nas redes sociais TikTok e Facebook, visto que um dos objetivos era atrair os estudantes para o ambiente virtual formal - o Moodle. A estratégia deu certo, observando-se um crescimento na participação dos alunos na plataforma formal

Além dos estudantes - público para o qual os vídeos foram criados - houve uma grande aceitação dos mesmos na rede social Facebook, sendo compartilhado por outros 
professores, que pediram consentimento para reuso. Esta etapa contribui para análise e validação do uso dos vídeos do TikTok no contexto educacional.

A Figura 4 apresenta um dos primeiros vídeos postados na rede social Facebook. Como pode-se observar, o vídeo foi curtido por mais de 300 pessoas, o que demonstra que o mesmo atingiu um público-alvo bem maior que os discentes, tendo 85 comentários e 4 compartilhamentos.

\section{Figura 4 - Print da postagem no Facebook contendo um dos vídeos do TikTok}

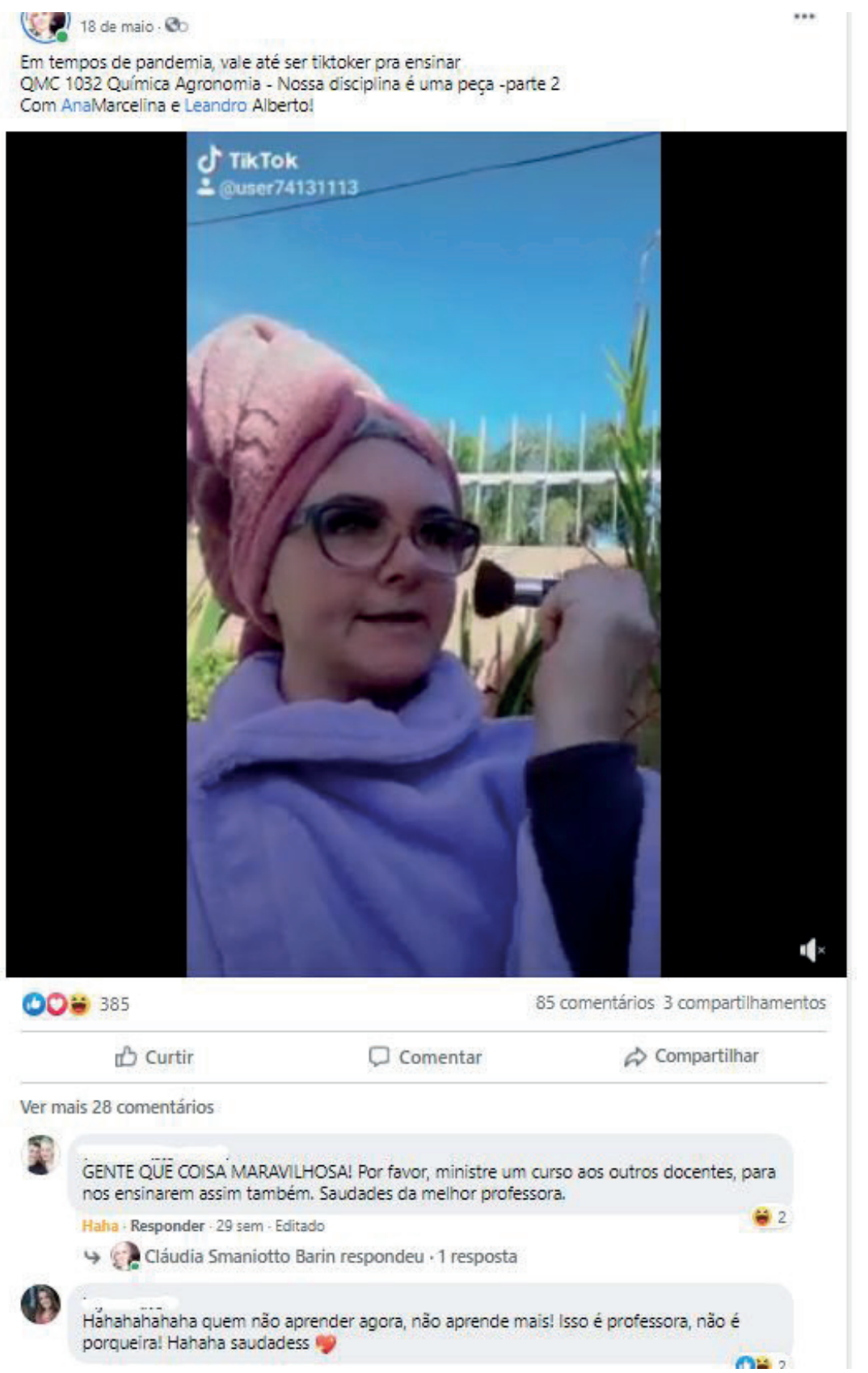

Fonte: os autores.

Destaca-se outros comentários que corroboram a aceitação da distribuição de conteúdos nesse formato: 
Parabéns muito tri essa aula até eu estou motivado a seguirei. (seguidor A)

Hahahahahaha quem não aprender agora, não aprende mais! Isso é professora (seguidor B)

Top de mais como não curtir uma aula assim (seguidor C)

Nem sei o que dizer!!! Penso que os professores me encantam diariamente! Vc está demais, é demais! Incrível! (seguidor D)

Eu to quase perdendo o trauma da química com seus vídeos!!!! Continua que tá delícia!!! (seguidor E)

Achei curto, Profa! Faz mais longo pra gente dar mais risada... ops aprender mais esse conteúdo... Gosto desse tema! (seguidor F)

Com base nos comentários da rede e o retorno dos estudantes às atividades online, pode-se afirmar que o uso de vídeos criativos curtos do TikTok, podem ser uma alternativa não apenas para despertar a atenção dos estudantes, mas para distribuição de conteúdos (avaliação). Como afirmam Rocha e Farias (2020) os vídeos curtos são pílulas de aprendizagem, que podem ser acessadas por meio dos dispositivos móveis diminuindo as dificuldades de sobrecarga cognitiva e de acessibilidade. Além disso, observa-se que os comentários corroboram a afirmativa de Rosado e Alves (2018), que o compartilhamento de saberes nas redes sociais pode contribuir para a valorização da profissão docente.

Na perspectiva da DBR, após cada vídeo produzido (design do produto) e sua implementação, era realizada uma avaliação do alcance dos mesmos, os comentários dos alunos, assim como o engajamento deles na plataforma Moodle. Não satisfeitos com interesse dos mesmos, após a disponibilização do conteúdo nesse formato durante um período, os alunos foram desafiados (numa perspectiva de redesign) a criarem um vídeo no TikTok que abordasse o conceito de Gravimetria, como pode ser visto na Figura 5.

\section{Figura 5 - Atividade Fórum propostas no Moodle}

\section{Hora do desafio}

Vimos essa semana a análise gravimétrica e chegou a vez de vocês me mostrarem que arrasam nas tecnologias.

A atividade dessa semana pode ser realizada de diferentes formas - você pode gravar um vídeo no celular, no Tiktok ou mesmo um podcast (usando o Podbean, ou Anchor), abordando a temática gravimetria.

Você poderá gravar algo sobre a importância da técnica, entrevistar alguém para nos contar sobre sua aplicação etc.

Vamos lá, porque aprender pode ser muito mais do que resolver exercícios.

Compartilhe sua produção aqui no fórum e comente a produção de seus colegas!

Acrescentar um novo tónico de discuscão

Inicialmente os mesmos apresentaram certa resistência para execução da atividade, que deveria ser compartilhada com os colegas no fórum do Moodle, mas após as duas primeiras postagens ele foram se sentindo motivados a participar da atividade, o que proporcionou uma aprendizagem efetiva do assunto, visto que além de criar o vídeo, os mesmos deveriam assistir aos vídeos dos colegas e comentar em suas postagens. 
Apesar dos estudantes serem considerados nativos digitais e serem usuários de redes sociais como o Facebook, Instagram e até mesmo o TikTok, para eles a atividade foi desafiadora, pois criar vídeos para o lazer é diferente de criar vídeos de conteúdo educacional. Uma das postagens pode contribuir para a compreensão da dimensão do desafio, conforme pode ser observado na Figura 6.

\section{Figura 6 - Vídeo produzido pela estudante "A" para o desafio da Gravimetria.}

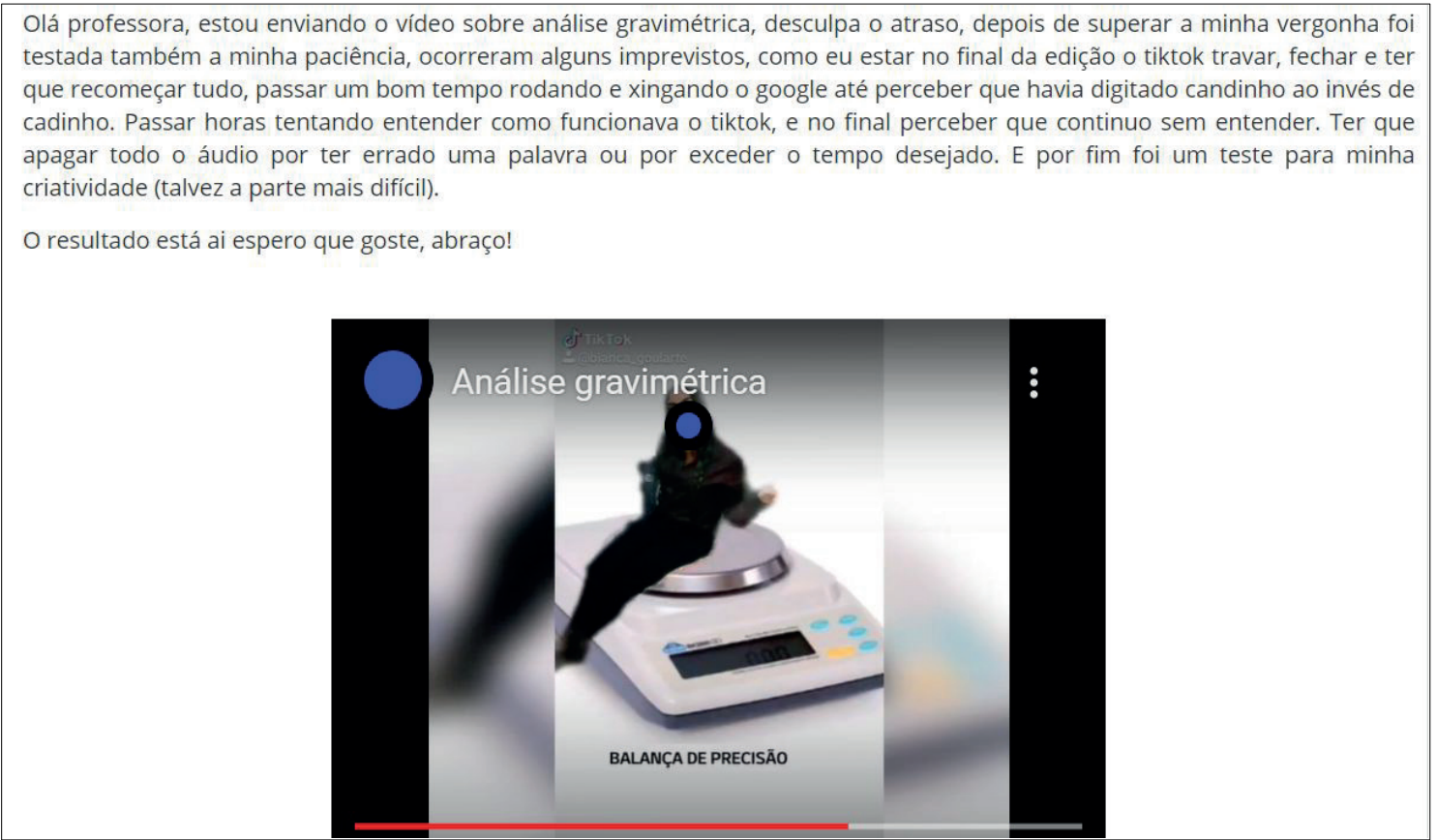

Fonte: estudante " $A$ "

No entanto, apesar de desafiadora a atividade proporcionou aos estudantes não apenas aprender o conteúdo proposto - Gravimetria, visto que assistiram a mais de 20 vídeos sobre a temática, mas contribuiu para romper com os paradigmas do processo avaliativo formal. Avaliar fora da caixa tem se constituído um dos maiores desafios durante a pandemia. Nesse sentido a produção de conteúdo requer dos estudantes não apenas apropriar-se da tecnologia, mas buscar informações sobre o conteúdo e compreender sua dinâmica para assim gravar sua produção. Além disso, os estudantes desenvolvem outras habilidades, como a criatividade, a resolução de problemas, a organização, o senso crítico, características tão importantes para o mundo do trabalho.

Assim, podemos inferir que o uso do TikTok no contexto educacional pode se dar em mais de uma dimensão, ou seja, tanto na distribuição de conteúdo, como nos processos avaliativos criativos, que requerem do estudante uma posição de protagonismo, rompendo com os velhos paradigmas da educação pautados na mera transmissão do conhecimento. Esses processos criativos requerem níveis cognitivos mais elevados, podendo contribuir de forma mais efetiva para a construção de saberes, visto que demandam maior esforço da memória de trabalho e, comumente acessam a memória de longo prazo. 


\section{Considerações Finais}

Os vídeos gravados na rede social TikTok despertaram o interesse dos estudantes pelo aprendizado, sendo que a participação dos mesmos nas atividades propostas aumentou em torno de $25 \%$ após a disponibilização dos vídeos no Moodle e na rede social Facebook.

A produção de vídeos curtos no TikTok pode ser uma alternativa viável para distribuição de conteúdo educacional, sendo um dos desafios dessa produção a roteirização, visto que o tempo para a abordagem do conteúdo é de apenas 60 segundos.

Por fim, os resultados obtidos nos permitem afirmar que os vídeos curtos do TikTok têm potencial para despertar o interesse dos estudantes pelo conteúdo. Outro fator relevante é a abordagem humorística contida nos vídeos, que contribui para tornar o aprendizado mais prazeroso.

\section{Referências}

BOTELHO KNEUBIL, Fabiana; PIETROCOLA, Maurício. A Pesquisa Baseada em Design: Visão Geral e Contribuições para o Ensino De Ciências. Investigações em Ensino de Ciências, v. 22, n. 2, 2017.

DA ROCHA, Carlos José Tridade; DE FARIAS, Sidilene Aquino. Metodologias Ativas de Aprendizagem Possíveis ao Ensino De Ciências E Matemática. REAMEC-Rede Amazônica de Educação em Ciências e Matemática, v. 8, n. 2, p. 69-87, 2020.

DE OLIVEIRA, Julie Charline Siqueira; NICHELE, Aline Grunewald. O Uso do Facebook como Ambiente Virtual de Aprendizagem no Ensino de Química Orgânica em Língua Inglesa. RENOTE-Revista Novas Tecnologias na Educação, v. 17, n. 3, p. 7181, 2019. Disponível em: < https://www.seer.ufrgs.br/renote/article/view/99428 $>$. Acesso em out. 2020. DOI: $<$ https://doi.org/10.22456/1679-1916.99428 $>$

FELCHER, Carla Denize Ott; BIERHALZ, Crisna Daniela Krause; FOLMER, Vanderlei. A utilização dos vídeos educacionais do YouTube na Licenciatura em Matemática: presencial e a distância. RENOTE-Revista Novas Tecnologias na Educação, v. 17, n. 1, p. 577-586, 2019. Disponível em: https://seer.ufrgs.br/renote/article/view/95950>. Acesso em out. 2020. DOI: $<\underline{\text { https://doi.org/10.22456/1679-1916.95950 } \geq}$

HERRINGTON, Jan.; MCKENNEY, Susan.; REEVES, Thomas.; OLIVER, Ron. Design-based research and doctoral students: Guidelines for preparing a dissertation proposal. In: Edith Cowan University. ECU Publications: 2007. Disponível em: $<$ http://doc.utwente.nl/93893/1/Designbased\%20research\%20and\%20doctoral\%20students.pdf $>$. Acesso em: 20 set. 2020.

MONTEIRO, Jean Carlos da Silva. Tiktok como Novo Suporte Midiático para a Aprendizagem Criativa. Revista Latino-Americana de Estudos Cientifico, v1, n.2, p.5-20, 2020.

MORAN, José Manuel. O Vídeo na Sala de Aula. Comunicação e Educação, v. 2, p. 27-35, 1995. 
ROSADO, Janaína; ALVES, Lynn. Circulação e Propagação de Informações: Professores Conectados no Facebook. RENOTE-Revista Novas Tecnologias na Educação, v. 16, n. 1, 2018. Disponivel em: $<$ https://seer.ufrgs.br/renote/article/view/86030>. Acesso em out. 2020. DOI: $<\underline{\text { https://doi.org/10.22456/1679-1916.86030> }}$

SOARES, Aline Bairros; BOTEGA, Sandra Palma; SANTOS, Leila Maria; ELLENSOHN, Ricardo Machado; BARIN, Claudia Smaniotto. Construindo saberes nas redes sociais. RENOTE-Revista Novas Tecnologias na Educação, v. 16, n. 1, 2018. Disponível em: https://seer.ufrgs.br/renote/article/view/85991>. Acesso em out. 2020. DOI: $<\underline{\text { https://doi.org/10.22456/1679-1916.85991> }}$

VALENTE, Geilsa. S. C et al. O ensino remoto frente às exigências do contexto de pandemia: Reflexões sobre a prática docente. Research, Society and Development, v. 9, n.9, 2020. Disponível em: $<$ https://rsdjournal.org/index.php/rsd/article/view/8153/7109>. Acesso em: $10 \mathrm{dez}$.

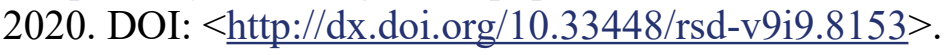

WANG, Feng.; HANNAFIN, Michael. J.. Design-based Research and TechnologyEnhanced Learning Environments. In: Educational Technology Research and Development, v. 53, n. 4, p. 5-23, 2005. Disponível em: $<$ https://ideascale.com/userimages/sub-1/898000/panel_upload_12279/30221206.pdf.> Acesso em: 20 de set. 2020.

WANG, Yunwen. Influence of camera view on TikTok users' presence, immersion, and adoption intent. Computers in Human Behavior, p. 106373, 2020. DOI $<$ https://doi.org/10.1016/j.chb.2020.106373 $>$. 